\title{
Editorial
}

\section{Regional Strength in CAM}

\section{Edwin L. Cooper}

\author{
Laboratory of Comparative Neuroimmunology, Department of Neurobiology, David Geffen School of Medicine \\ at UCLA, University of California, Los Angeles, Los Angeles, California 90095-1763, USA
}

Several years ago, I spent a sabbatical at University of Modena, Italy, living nearby in the famous university town of Bologna. While there, firm roots were established to search for anticancer molecules and new wave antibiotics $(1,2)$. Far from my radar screen was another adventure, now unfolding in Bologna and even for $e C A M$. Little did I realize that another visit was simmering and taking shape-long before the birth of $e C A M$ and the appointment of a strong group of editorial board members focused around that region of Italy, all professors and or practitioners in nearby universities: Andrea Cossarizza, Modena, Claudio Franceschi, Carlo Ventura, Paulo Roberti di Sarsina, Carla Maria Giovanardi, Bologna, Paulo Bellavite, Verona, Francesco Marotta, Emilio Minelli, Milan. All are contributing forcefully to uncovering the basic science and clinical practice of CAM.

In a sense the seeds for this new plant were nurtured even earlier when Claudio Franceschi and I first met as immunologists on leave at the Karolinska Institute, Stockholm, I on my first sabbatical as a Guggenheim Fellow from UCLA and Claudio, a younger post doc. Both of us are immunologists. I worked in the laboratory of Goran and Erna Moller and Claudio with George and Eva Klein. This was in 1970-71 and we remained in sporadic contact by my requesting some of Claudio's previously published histopathology of spleens from an exotic animal for my first book, Comparative Immunology published by Prentice Hall, in 1976 one of several books in the Immunobiology Series. We met on other occasions mostly through strong mutual interests in the blooming subject of neuoroendocrine immunology and there luck struck again where at one symposium, I became immediate friends with Andrea Cossarizza MD then a PhD student working with

For reprints and all correspondence: Edwin L. Cooper, Ph.D., Sc.D. Distinguished Professor and Founding Editor in Chief, eCAM Laboratory of Comparative Neuroimmunology, Department of Neurobiology, David Geffen School of Medicine at UCLA, University of California, Los Angeles, Los Angeles, California 90095-1763, USA. Tel: +1-310-825-9567;

Fax: +1-310-825-2224; E-mail: cooper@mednet.ucla.edu; ecam@mednet.ucla.edu
Claudio. Move now from 1990 to 1993 and we witness my decision to come to University of Modena for my fourth sabbatical in Claudio's lab.

Originally wanting to work on immunorecognition in snails (sharing some work also with another collaborator, Enzo Ottaviani), as luck would have it I decided almost impulsively to work on the earthworm with Andrea. Why? Snails were in hibernation and could not be collected during the fall of 1993. Besides, I had just finished supervising another PhD student Michael Suzuki at UCLA on the natural cytotoxicity of earthworm coelomocytes, so all I needed was to convince (and this was not at all difficult) Andrea to do some "quick and dirty experiments" and confirm Suzuki's thesis, co-culturing earthworm leukocytes with K562, a common tumor cell line useful for assaying natural cytotoxicity. I wanted especially to search for the evolutionary precursors of NK cells.

This turned out to be an outstanding adventure, demonstrating for the first time the distinct separation of phagocytosis from NK cell killing of foreign tissue antigens. Our work supported Burnet's view of immunologic surveillance and brought back into focus once again since Metchnikoff, the crucial position of invertebrates and animal models in understanding the basic science underlying immune responses, i.e. the prominent role of innate immunity as essential for survival of species (3). During that period in Italy I also spent some time with Prof Nicolo Parrinello, University of Palermo working on the neuroendocrine consequences of stress induced by crowding on the immune system of fish. It was also of special interest to look at the antimicrobial peptides of tunicates (actually some of these are useful as anticancer therapeutics (4).

In the meantime eCAM was born and I turned internationally for experts to serve as Editorial Board members and once again found myself seriously considering this region of Italy (5-8). Claudio Franceschi brings to the board his expertise in senescence, having coined the word centenarians; at the moment he is exploring the possible role of curcumin in apoptosis (9). Clearly aging populations could be real targets for CAM approaches. Andrea Cossarizza and I are once again 
collaborating closely on quercetin, a flavonoid and differential apoptotic activity on leukemic cells and peripheral blood lymphocytes (10,11). Stem cells reach a high level of relevance to CAM (12) through the work of Carlo Ventura (13) in which he proposes cell models with receptors that may be vulnerable to outside influences. This captures the basic science approaches to CAM with the ultimate promise of evidence based, not all clinical but highly relevant.

More recently the importance of acupuncture is evident in the influence of Carlo Maria Giovarnardi. He is in charge of the Fondazione Mateo Ricci, an institution dedicated to the diffusion of acupuncture and traditional Chinese medicine. Moving somewhat eastward toward Venice, Paulo Bellavite is exploring all aspects of basic science in relation to homeopathy (14). And then there are the efforts of Emilio Minelli and Francesco Marotta in Milan. Turning to more clinical aspects, we are ever mindful of the importance of networking throughout Italy and internationally by the efforts of Paulo Roberti di Sarsina that are particularly important here (15).

Let me state at the outset that by briefly focusing on this region, there is neither particular bias toward CAM in Italy nor any other country. UCLA where I am based has a Collaborative Centers of Integrative Medicine (CCIM) and there are certain other similar consortia. There is a large focus in parts of Asia where our travels have been rather extensive, thanks to generous invitations. It is only fortuitous that I have been able to combine my own research interests somewhat independent of CAM coupled with this current sabbatical (Senior Visiting Scientist, Institute for Advanced Studies, University of Bologna;hosted by Claudio Francheschi) with efforts to stimulate and integrate more CAM activities. It is this spirit of inquiry, my own, some of which overlap with CAM that makes this position of Editor in Chief so very rewarding!

\section{References}

1. Cooper EL, Cossarizza A, Suzuki MM, Salvioli S, Capri M, Quaglino D, Franceschi C. Autogeneic but not allogeneic earthworm effector coelomocytes kill the mammalian tumor cell target K562. Cell Immunol 1995; $166: 113-122$.

2. Cossarizza A, Cooper EL, Suzuki MM, Salvioli S, Capri M, Gri G, Quaglino D, Franceschi C. Earthworm leukocytes that are not phagocytic and cross-react with several human epitopes can kill human tumor cell lines. Exptl Cell Res 1996;224:174-182.

3. Cooper EL, Kauschke E, Cossarizza A. Digging for innate immunity since Darwin and Metchnikoff. Bioessays 2002;24:319-333.

4. Simmons TL, Andrianasolo E, McPhail K, Flatt P, Gerwick WH. Marine natural products as anticancer drugs. Mol Cancer Ther 2005; 4: 333-342.

5. Cooper EL. Complementary and Alternative Medicine, When Rigorous, can be Science. eCAM 2004;1:1-4.

6. Cooper EL. Drug Discovery, CAM and Natural Products. eCAM 2004;1: 215-217.

7. Cooper EL. Bioprospecting: a CAM Frontier. eCAM 2005;2:1-3.

8. Cooper EL. CAM, eCAM, Bioprospecting: The 21st Century Pyramid. eCAM 2005;2:125-127.

9. Magalska A, Sliwinska M, Szczepanowska J, Salvioli S, Franceschi C, Sikora E. Resistance to apoptosis of HCW-2 cells can be overcome by curcumin- or vincristine-induced mitotic catastrophe. Int J Cancer 2006 May 23; [Epub ahead of print].

10. Lugli E, Troiano L, Ferraresi R, Roat E, Prada N, Nasi M, Pinti M, Cooper EL, Cossarizza A. Characterization of cells with different mitochondrial membrane potential during apoptosis. Cytometry A 2005;68:28-35.

11. Ferraresi R, Troiano L, Roat E, Lugli E, Nemes E, Nasi M, Pinti M, Fernandez MI, Cooper EL, Cossarizza A. Essential requirement of reduced glutathione (GSH) for the anti-oxidant effect of the flavonoid quercetin. Free Radic Res 2005;39:1249-1258.

12. Cooper EL. Stem Cells and CAM eCAM Advance Access published on May 4, 2006. eCAM 2006;3:167-169.

13. Ventura C. CAM and Cell Fate Targeting: Molecular and Energetic Insights into Cell Growth and Differentiation. eCAM 2005;2:277-283.

14. Bellavite P, Conforti A, Piasere V, Ortolani R. Immunology and Homeopathy. 1. Historical Background. eCAM 2005;2:441-452.

15. Roberti P. PINUS Association Symposium: 'Medicine, the New Paradigms of Science': May 5-8, 2005, Ravenna, Italy, Teatro Rasi. eCAM 2005;2:421-424. 


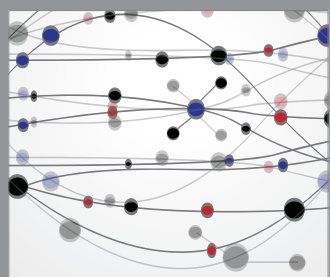

The Scientific World Journal
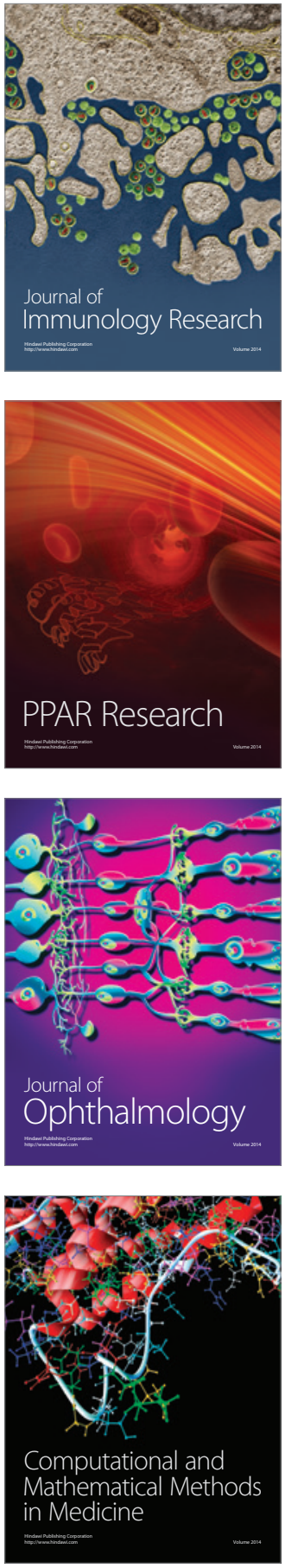

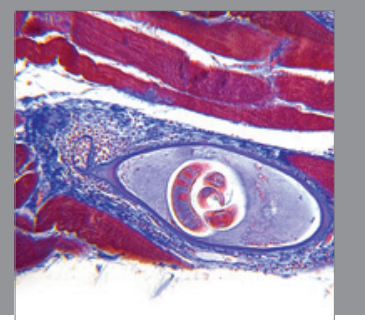

Gastroenterology

Research and Practice
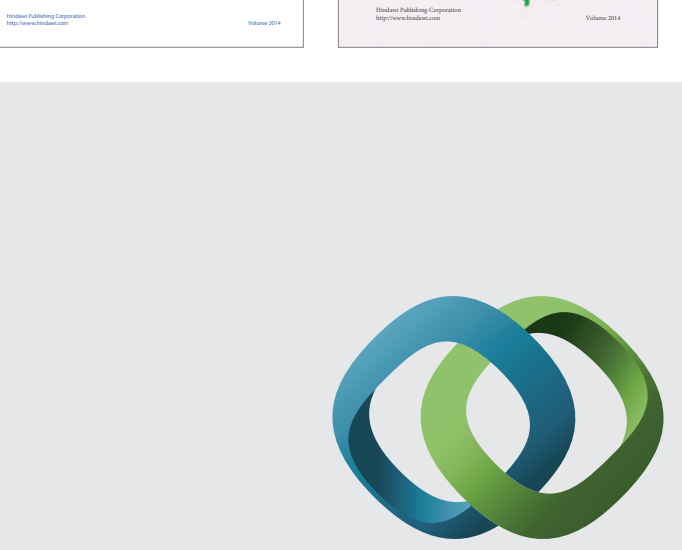

\section{Hindawi}

Submit your manuscripts at

http://www.hindawi.com
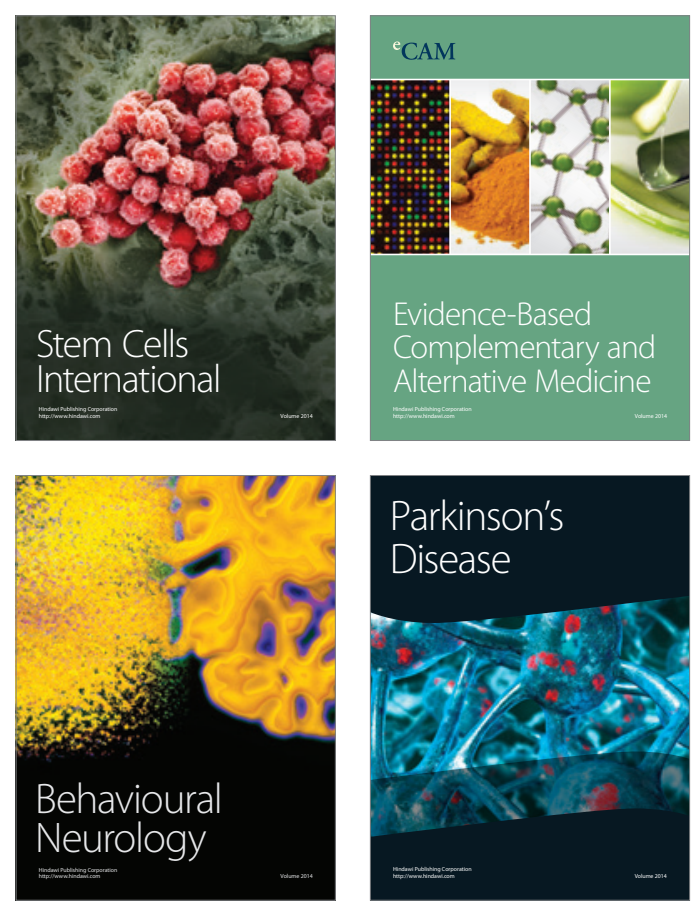

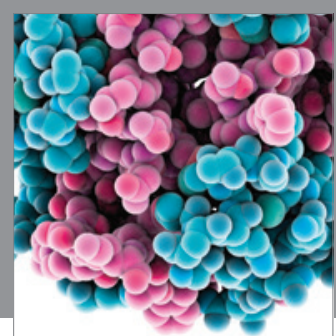

Journal of
Diabetes Research

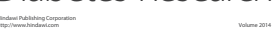

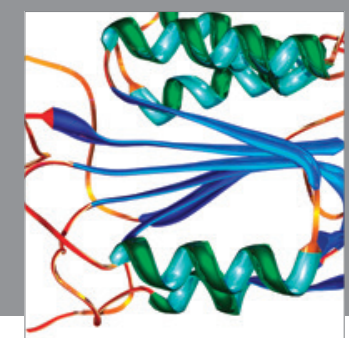

Disease Markers
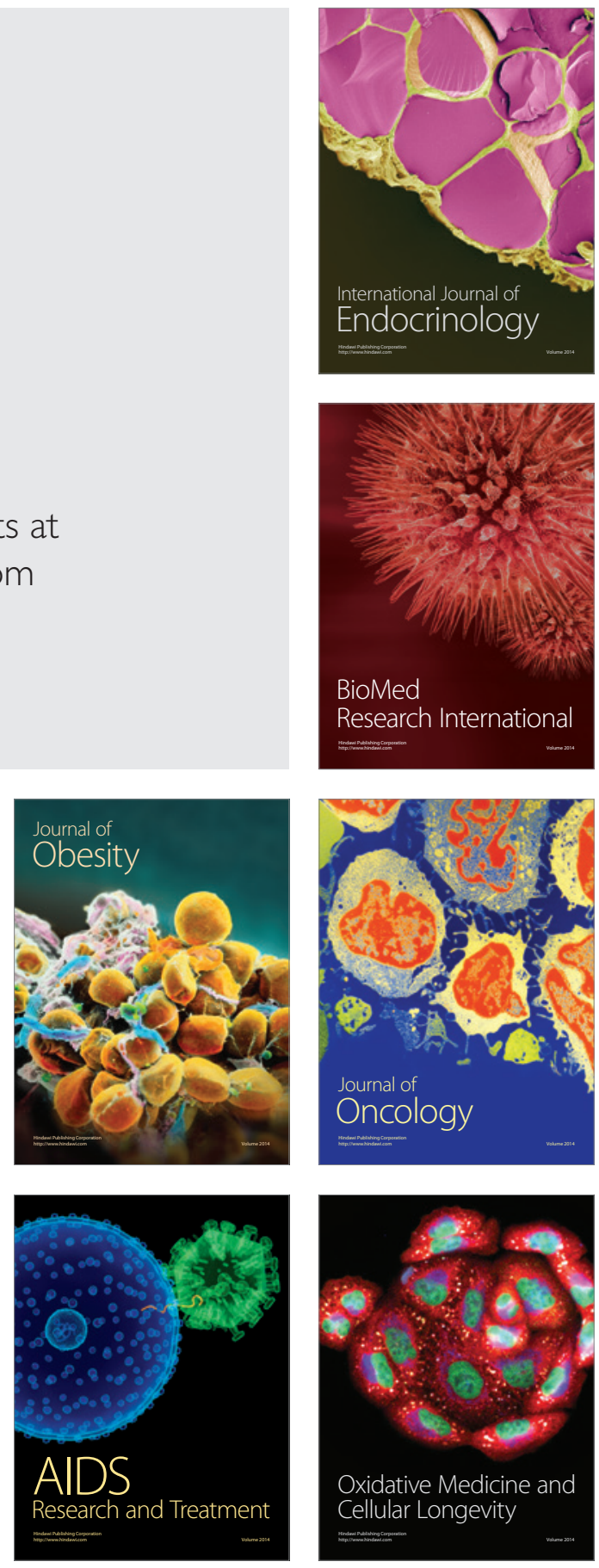